\title{
Article \\ Quercetin Induces Anticancer Activity by Upregulating Pro-NAG-1/GDF15 in Differentiated Thyroid Cancer Cells
}

\author{
Yukyung Hong ${ }^{1} \mathbb{D}$, Jaehak Lee ${ }^{1} \mathbb{D}$, Hyunjin Moon $^{1} \mathbb{D}$, Chang H. Ryu ${ }^{2}$, Jungirl Seok ${ }^{2} \mathbb{D}$, Yuh-Seog Jung $^{2}$, \\ Junsun Ryu ${ }^{2, *}$ and Seung J. Baek ${ }^{1, *}$ D
}

1 College of Veterinary Medicine and Research Institute for Veterinary Science, Seoul National University, Seoul 08826, Korea; hyu1154@naver.com (Y.H.); ljh930307@snu.ac.kr (J.L.); hyjin1995@naver.com (H.M.)

2 Center for Thyroid Cancer, Department of Otolaryngology-Head and Neck Surgery Research Institute and Hospital, National Cancer Center, Goyang-si 10408, Korea; changhwanr@ncc.re.kr (C.H.R.); jseok@ncc.re.kr (J.S.); jysorl@ncc.re.kr (Y.-S.J.)

* Correspondence: jsryu@ncc.re.kr (J.R.); baeksj@snu.ac.kr (S.J.B.); Tel.: +82-31-920-1684 (J.R.); $+82-2-880-1195$ (S.J.B.)

check for

updates

Citation: Hong, Y.; Lee, J.; Moon, H.; Ryu, C.H.; Seok, J.; Jung, Y.-S.; Ryu, J.; Baek, S.J. Quercetin Induces

Anticancer Activity by Upregulating Pro-NAG-1/GDF15 in Differentiated Thyroid Cancer Cells. Cancers 2021, 13, 3022. https://doi.org/10.3390/ cancers 13123022

Academic Editors: Chankwon Jung and Andrey Bychkov

Received: 19 April 2021

Accepted: 14 June 2021

Published: 16 June 2021

Publisher's Note: MDPI stays neutral with regard to jurisdictional claims in published maps and institutional affiliations.

Copyright: (c) 2021 by the authors. Licensee MDPI, Basel, Switzerland. This article is an open access article distributed under the terms and conditions of the Creative Commons Attribution (CC BY) license (https:/ / creativecommons.org/licenses/by/ $4.0 /)$.
Simple Summary: Thyroid cancer is one of the most common cancers worldwide, and its incidence has increased over the last few decades. It is difficult to diagnose different types of thyroid cancer. Tumor tissues from papillary thyroid cancer patient showed higher expression of mature NAG-1, whereas adjacent normal tissues showed higher expression of pro-NAG-1. Several anti-cancer compounds increased pro-NAG-1 expression in thyroid cancer cell line. Quercetin $\left(3,3^{\prime}, 4^{\prime}, 5,7\right.$-pentahydroxyflavone $)$ is a flavonoid that is a major component of various plants, including raspberries, grapes, and onions. Quercetin induced apoptosis by inducing only pro-NAG-1 expression, but not mature NAG-1, mediated by the transcription factor C/EBP. This study indicates that pro-NAG-1 could be used as a useful biomarker for thyroid cancer and also provides a potential therapeutic target for the treatment of thyroid cancer with quercetin.

Abstract: Although the treatment of thyroid cancer has improved, unnecessary surgeries are performed due to a lack of specific diagnostic and prognostic markers. Therefore, the identification of novel biomarkers should be considered in the diagnosis and treatment of thyroid cancer. In this study, antibody arrays were performed using tumor and adjacent normal tissues of patients with papillary thyroid cancer, and several potential biomarkers were identified. Among the candidate proteins chosen based on the antibody array data, mature NAG-1 exhibited increased expression in tumor tissues compared to adjacent normal tissues. In contrast, pro-NAG-1 expression increased in normal tissues, as assessed by western blot analysis. Furthermore, pro-NAG-1 expression was increased when the thyroid cancer cells were treated with phytochemicals and nonsteroidal anti-inflammatory drugs in a dose-dependent manner. In particular, quercetin highly induced the expression of pro-NAG-1 but not that of mature NAG-1, with enhanced anticancer activity, including apoptosis induction and cell cycle arrest. Examination of the NAG-1 promoter activity showed that p53, C/EBP $\alpha$, or C/EBP $\delta$ played a role in quercetin-induced NAG-1 expression. Overall, our study indicated that NAG-1 may serve as a novel biomarker for thyroid cancer prognosis and may be used as a therapeutic target for thyroid cancers.

Keywords: thyroid cancer; quercetin; pro-NAG-1; GDF15; C/EBP; mature NAG-1

\section{Introduction}

The incidence of thyroid cancer has increased in recent years, being the most commonly detected cancer in the USA (52,070 new cases in 2019) [1]. It is also the second most frequently diagnosed cancer in Korea [2]. Cancer biomarkers can be classified into three broad categories: DNA, RNA, and protein markers. New biomarkers for cancer research are highly desirable, as early detection and correct diagnosis are essential for 
cancer treatment. Several potential biomarkers of thyroid cancer have been reported, including BRAFV600E and RAS genes in papillary thyroid cancer (PTC) [3,4], paired box 8 (PAX8), peroxisome proliferator-activated receptor $\gamma(P P A R \gamma)$ fusion gene [5], loss of heterozygosity $(\mathrm{LOH})$ on chromosome $3 \mathrm{p}$ and $7 \mathrm{q}$ loci, and $R A S$ mutations in follicular thyroid cancer (FTC) [6]. However, the identification of additional biomarkers for thyroid cancer is still needed.

NAG-1 is a TGF- $\beta$ superfamily cytokine with multiple roles in several diseases [7]. Two major forms of NAG-1 have been identified: a pro-form and a mature form [8]. The biological activity of mature form has been well characterized in obesity, as the mature/secreted form binds to the GFRAL receptor, leading to a reduction in appetite in the brain [9]. Additionally, the mature form of NAG-1 may play a role in pro-tumorigenic activity in some cancers $[10,11]$. However, the biological activity of the pro-form has not been well elucidated. The pro-forms of NAG-1 are located in the nucleus where they control the transcription of Smad target genes [12]. Furthermore, pro-NAG-1 alters the mitochondrial membrane potential in the cytoplasm, leading to cell death [13]. Thus, two forms of NAG-1 exhibit different activities in cancer; the pro-form shows anticancer activity, whereas the mature form shows pro-cancer activity during tumorigenesis [14]. In addition, the level of pro-NAG-1 was increased by several phytochemicals and plant extracts [15-19], providing a potential biomarker for anticancer compounds.

Quercetin (3,3', 4',5,7-pentahydroxyflavone) is a flavonoid that is a major component of various plants, including raspberries, red grapes, and onions [20]. This molecule is known to have many functions, such as antioxidant, pro-apoptotic, anti-inflammatory, antiangiogenic, and anticancer activities. Quercetin can cause cell cycle arrest and apoptosis, leading to inhibition of tumor growth, especially in breast, pancreatic, prostate, liver, and thyroid cancers [21-25]. Additionally, administration of sorafenib with quercetin in thyroid cancer cells can lower the dose and decrease the proliferation, adhesion, and migration properties [26]. However, the exact mechanism by which quercetin exerts this effect has not been studied, thus warranting follow-up studies.

Here, we found that the pro-form of NAG-1 is more expressed in normal thyroid tissues than in adjacent cancer tissues in papillary tumors. Furthermore, assessment of several anticancer compounds for pro-NAG-1 induction showed that quercetin is a bioactive compound that induces the expression of pro-NAG-1 but not that of mature NAG-1 in thyroid cancer cells. Moreover, quercetin induced apoptosis by inducing proNAG-1 expression, mediated by the transcription factor C/EBP. Our results indicate that pro-NAG-1 could be used as a useful biomarker for thyroid cancer and also provide a potential therapeutic target for the treatment of thyroid cancer with quercetin.

\section{Materials and Methods}

\subsection{Cell Culture and Reagents}

SW480, HEK293, U2OS, and BT-20 cells were purchased from the American Type Culture Collection (ATCC), whereas TPC-1, BCPAP, and HTori-3 cells were obtained from Gary Clayman (MD Anderson, Houston, TX, USA). These cells were tested by ATCC for post-freeze viability, growth properties, morphology, mycoplasma contamination, species determination (cytochrome c oxidase I assay and short tandem repeat analysis), sterility test, and human pathogenic virus testing. The cell lines were resuscitated immediately upon receiving and frozen in aliquots in liquid nitrogen. TPC-1, BCPAP, HTori-3, SW480, and BT-20 cells were cultured in Roswell Park Memorial Institute (RPMI)-1640 medium supplemented with 10\% fetal bovine serum (FBS; Thermo Fisher Scientific, Waltham, MA, USA) and 1\% penicillin/streptomycin (Gibco, Thermo Fisher Scientific, Waltham, MA, USA). U2OS cells were cultured in McCoy's 5A medium supplemented with 10\% FBS and 1\% penicillin/streptomycin. HEK293 cells were cultured in Dulbecco's modified Eagle's medium (DMEM) supplemented with 10\% FBS and 1\% penicillin/streptomycin. All cultured cells were maintained at $37^{\circ} \mathrm{C}$ under humid conditions with $5 \% \mathrm{CO}_{2}$. Dimethyl sulfoxide (DMSO) was purchased from Biosesang (Seongnam-si, Korea), while trans-chalcone 
sulindac sulfide, piroxicam, ibuprofen, diclofenac, and acetaminophen were obtained from Sigma-Aldrich (St. Louis, MO, USA). Resveratrol was supplied by Calbiochem (San Diego, CA, USA) and tolfenamic acid by Cayman Chemical Company (Ann Arbor, MI, USA). Meloxicam, naproxen, and apigenin were purchased from Tokyo Chemical Industry (Tokyo, Japan). Quercetin, naringenin, and kaempferol were purchased from MP Biomedicals LLC (Santa Ana, CA, USA). Genistein was obtained from Acros Organics (Geel, Belgium).

\subsection{Tissue Samples}

The surgical thyroid tissues used in this study were surgical samples provided by the National Cancer Center (Goyang-si, Korea), in the form of a pair of tumors with adjacent normal tissue (Table 1). These tissue samples were collected from patients with papillary thyroid carcinoma (PTC) and subsequently stored at $-80^{\circ} \mathrm{C}$. This study was approved by the Institutional Review Board of the National Cancer Center (NCC-1810150), and all the methods were conducted in accordance with the relevant guidelines and regulations.

Table 1. Patient sample information used in this study.

\begin{tabular}{cccc}
\hline Patient Number & Gender & Age at Time of Surgery & Type of Thyroid Cancer \\
\hline 2652 & M & 35 & Papillary carcinoma \\
4215 & F & 56 & Papillary microcarcinoma \\
2517 & M & 34 & Papillary carcinoma \\
\hline
\end{tabular}

\subsection{Antibody Array}

Whole proteins were extracted from thyroid tissues by sonication in radioimmunoprecipitation assay (RIPA) buffer (GenDEPOT, Katy, TX, USA) supplemented with proteinase and phosphatase inhibitors. The antibody array was performed using a RayBio ${ }^{\circledR}$ C-Series Human Cancer Discovery Antibody Array 3 (RayBiotech, Peachtree Corners, GA, USA) according to the manufacturer's protocol.

\subsection{Protien Isolation and Western Blot Analysis}

Cells were grown to $80 \%$ confluence and then treated with the indicated compounds. After $24 \mathrm{~h}$ of incubation with serum-free media, protein lysates were obtained using RIPA buffer supplemented with proteinase and phosphatase inhibitors and separated on sodium dodecyl sulfate-polyacrylamide electrophoresis (SDS-PAGE) gels (10, 12, and 15\% gels for tissue samples and $12 \%$ gels for BCPAP cells). To obtain conditional media, cells were grown in a $10 \mathrm{~cm}$ culture dish with $10 \mathrm{~mL}$ of serum-free media and incubated for $24 \mathrm{~h}$. The media were harvested, and the cell debris was removed and concentrated using an Amicon Ultra15 (UFC901024; Merck Millipore Ltd., Tullagreen, Carrigtwohill, County Cork, Ireland). The separated protein bands were transferred onto nitrocellulose membranes (GVS filter technology, Zola Predosa BO, Italy) and blocked with TBS buffer containing $0.05 \%$ Tween 20 (TBS-T) with $5 \%$ non-fat milk at room temperature for $1 \mathrm{~h}$, followed by overnight incubation with an appropriate primary antibody in TBS-T containing $5 \%$ non-fat milk at $4{ }^{\circ} \mathrm{C}$. The primary antibodies used were anti-NAG-1 (specific to both pro-NAG-1 and mature NAG1) [8], anti-galectin-3 (sc-32790; Santa Cruz Biotechnology, Santa Cruz, CA, USA), antiosteoprotegerin (OPG; sc-390518; Santa Cruz Biotechnology, Santa Cruz, CA, USA), antiTIMP-1(sc-6832; Santa Cruz Biotechnology, Santa Cruz, CA, USA), anti-GAPDH (sc-47724; Santa Cruz Biotechnology, Santa Cruz, CA, USA), and anti- $\beta$-actin (sc-47778; Santa Cruz Biotechnology, Santa Cruz, CA, USA). The membranes were washed three times with TBS-T buffer for $10 \mathrm{~min}$ and incubated with secondary antibodies dissolved in TBS-T buffer containing 5\% non-fat milk at room temperature for $2 \mathrm{~h}$. The membranes were washed again, and protein expression was detected by chemiluminescence using an enhanced chemiluminescence (ECL) western blotting detection reagent (Thermo Fisher Scientific, Waltham, MA, USA) on a chemiluminescence analyzer, Alliance Q9 Advanced (UVTEC CAMBRIDGE, Cambridge, England, UK) according to the manufacturer's instructions. 


\subsection{Reverse Transcriptase Quantitative Polymerase Chain Reaction (RT-qPCR)}

RNA was isolated with TRIzol reagent (Ambion, Foster City, CA, USA) according to the manufacturer's instructions, and reverse transcription was performed using the Verso cDNA Synthesis Kit (Thermo Fisher Scientific, Waltham, MA, USA) according to the manufacturer's instructions. RT-qPCR was performed using the QuantStudio 1 Real-Time PCR System using PowerUp ${ }^{\mathrm{TM}}$ SYBR ${ }^{\mathrm{TM}}$ Green Master Mix (A25741; Thermo Fisher Scientific, Waltham, MA, USA) with NAG- 1 forward ( $5^{\prime}$-GACCCTCAGAGTTGCACTCC- $\left.3^{\prime}\right)$ and reverse (5'-GCCTGGTTAGCAGGTCCTC-3') primers. Expression of NAG-1 was corrected by GAPDH expression (forward primer: 5'-GAAGGTGAAGGTCGGAGTCA-3', reverse primer: $5^{\prime}$-GACAAGCTTCCCGTTCTCAG-3'). All reactions were performed in triplicate, and the relative expression level of NAG-1 was calculated using the $2^{-\Delta \Delta C t}$ method.

\subsection{Dual-Luciferase Assay}

BCPAP cells were seeded in a 24-well plate and incubated for $24 \mathrm{~h}$ at $37^{\circ} \mathrm{C}$. Four luciferase constructs were used (pNAG-1 -133/+70/LUC, pNAG-1 -133/+41/LUC, pNAG$1-474 /+41 / \mathrm{LUC}$, and pNAG-1 -1086/+41/LUC) [27]. For the co-transfection experiments, each luciferase construct with the empty vector, $\mathrm{p} 53, \mathrm{ATF} 3, \mathrm{CREB}, \mathrm{RAR} \alpha, \mathrm{C} / \mathrm{EBP} \alpha, \mathrm{C} / \mathrm{EBP} \delta$, or EGR-1 expression vector was transfected into BCPAP cells, and either DMSO or quercetin $(10$ and $50 \mu \mathrm{M})$ was added to the transfected cells in serum-free media. After $24 \mathrm{~h}$, the media were removed, and the cells were washed twice with $1 x$ PBS. Then, $200 \mu \mathrm{L}$ of $1 \mathrm{x}$ passive lysis buffer was added to each well, and the plate was shaken until the cells were detached completely on ice. The cell lysate was transferred to a new tube and centrifuged at $12,000 \times g$ for $15 \mathrm{~s}$. Luciferase activity was measured using a Dual-Luciferase kit (Promega, Madison, WI, USA) according to the manufacturer's protocol.

\subsection{Cytotoxicity Assay Using High-Content Screening}

Eight thousand BCPAP cells were seeded on a poly D-Lysine-coated 96-well plate and incubated overnight. Cells were treated with compounds in serum-free RPMI 1640 medium for $24 \mathrm{~h}$ at $37^{\circ} \mathrm{C}$. After washing with Hanks' balanced salt solution (HBSS; Sigma-Aldrich, St. Louis, MO, USA), cells were stained with $1 \mu \mathrm{g} / \mathrm{mL}$ Hoechst 33342 (Sigma-Aldrich, St. Louis, MO, USA), $100 \mathrm{nM}$ SYTOX ${ }^{\circledR}$ Green Nucleic Acid Stain (Thermo Fisher Scientific, Waltham, MA, USA), and $25 \mathrm{nM}$ MitoTracker ${ }^{\circledR}$ Orange CMTMRos (Thermo Fisher Scientific, Waltham, MA, USA) in HBSS for $30 \mathrm{~min}$ at $37^{\circ} \mathrm{C}$. Cells were washed with HBSS twice and analyzed using the CellInsight CX7 LZR High-Content Screening (HCS) Platform (Thermo Fisher Scientific, Waltham, MA, USA) at 200× magnification.

\subsection{Apoptosis Analysis by Flow Cytometry}

BCPAP cells were cultured in a 6-well plate until they reached $60-80 \%$ confluence. The cells were treated with the compound in serum-free media and incubated for $24 \mathrm{~h}$. After washing and trypsinization, cells were stained with FITC Annexin V Apoptosis Detection Kit with propidium iodide (PI; BioLegend, San Diego, CA, USA) according to the manufacturer's protocol. The cells were then analyzed using Sony SH800 Cell Sorter (Sony Biotechnology Inc., Tokyo, Japan). The data is analyzed by FlowJo software (BD Life Sciences, Franklin Lakes, NJ, USA).2.9. Cell Cycle Analysis

Cells grown on a 6-well plate to $100 \%$ confluence were treated with the compounds in serum-free media for $24 \mathrm{~h}$. Then, the cells were harvested in a microcentrifuge tube and fixed with $0.5 \mathrm{~mL}$ of cold $70 \% \mathrm{EtOH}$ (Merck, Billerica, MA, USA) for $1 \mathrm{~h}$. Cells were collected by centrifugation and resuspended in $0.5 \mathrm{~mL}$ of phosphate-buffered saline (PBS) with $0.25 \%$ Triton-X 100 (Glentham Life Sciences Ltd., Corsham, Wiltshire, UK) for $15 \mathrm{~min}$ on ice. After centrifugation, cell pellets were resuspended in PBS $(0.5 \mathrm{~mL})$ containing $10 \mu \mathrm{g} / \mathrm{mL}$ RNase A (iNtRON Biotechnology, Seongnam, Gyeonggi Province, Korea) and $20 \mathrm{\mu g} / \mathrm{mL}$ PI (Invitrogen, Carlsbad, CA, USA) and incubated for $30 \mathrm{~min}$ in the dark. Cells were analyzed by Sony SH800 Cell Sorter (Sony Biotechnology Inc., Tokyo, Japan). The data 
is analyzed by FlowJo software (BD Life Sciences, NJ, USA).2.10. Transient Transfection of NAG-1 Construct

BCPAP cells were seeded in $60 \mathrm{~mm}$ dishes and transiently transfected with PolyJet Transfection Reagent (SignaGen, Gaithersburg, MD, USA) according to the manufacturer's protocol. After $24 \mathrm{~h}$ post-transfection, serum-free media containing DMSO and quercetin $(1,10$, and $50 \mu \mathrm{M})$ was added to the dishes. After $24 \mathrm{~h}$ of treatment with the compounds, the cells were harvested and analyzed by western blotting.

\subsection{Enzyme-Linked Immunosorbent Assay (ELISA)}

Plasma NAG-1 levels were measured using the Human GDF15 Quantikine ELISA Kit (DGD150; R\&D Systems, Minneapolis, MN, USA). Samples, reagents, and buffers were prepared according to the manufacturer's instructions. The detection sensitivity of NAG-1 was $4.39 \mathrm{pg} / \mathrm{mL}$, and the assay range was $23.4-1500 \mathrm{pg} / \mathrm{mL}$. To determine the optical density, a microplate reader was used to measure the intensity of the wells. The microplate reader was set to $450 \mathrm{~nm}$ and corrected by subtracting the intensity at $570 \mathrm{~nm}$. The concentration of each sample was calculated using a standard curve.

\subsection{Statistical Analysis}

Statistical analysis was conducted using Microsoft Office Excel, SPSS, and GraphPad Prism 8. Unpaired Student's $t$-test and one-way analysis of variance were used to analyze the data. For all analyses, results were considered significant at $p<0.05\left({ }^{*} p<0.05\right.$, ** $p<0.01$, and $\left.{ }^{* *} p<0.001\right)$.

\section{Results}

\subsection{Identification of Differentially Expressed Proteins in Thyroid Normal and Tumor Tissues}

To identify novel biomarkers in thyroid cancer, we performed an antibody array using normal human thyroid and tumor tissues. Tumor and adjacent normal tissues were obtained from patients with papillary thyroid cancer, and an antibody array was performed. Four candidate proteins, galectin-3, NAG-1, TIMP-1, and osteoprotegerin (OPG), were identified as potential biomarkers of thyroid cancer (Figure 1A). The protein expression of galectin-3, TIMP-1, and NAG-1 was higher in tumor tissues than in normal tissues. In contrast, OPG expression was higher in normal tissues than in tumor tissues. To confirm the results of the antibody array, western blot analysis was performed using the proteins extracted from three patients with papillary cancer (Table 1). The expression of OPG was higher in normal tissues, whereas that of galectin-3 and TIMP-1 was higher in tumor tissues (Figure 1B). Interestingly, two forms of NAG-1/GDF15 were detected in the tissues. Mature NAG-1 was expressed more in tumor tissues, whereas pro-NAG-1 exhibited higher expression in normal tissues. Since NAG-1 is expressed as a pro- $(\sim 35 \mathrm{kDa})$ and a mature form $(\sim 12 \mathrm{kDa})$, the antibody array data were consistent with the mature form of NAG-1. Pro-NAG-1 and mature-NAG-1 have been reported to exhibit different biological activities in tumorigenesis $[7,14]$. Since mature NAG- 1 has been detected in the antibody array and mature serum NAG-1 is linked to thyroid pro-tumorigenesis [28], we measured serum NAG-1 levels to identify the linkage in different types of thyroid cancer: non-aggressive benign thyroid nodules (BTN: FA and $\mathrm{NH}$ ) and aggressive differentiated thyroid cancer (DTC: FVPTC, PTC, and FTC). Serums from forty-nine patients (Figure S1E) were obtained, and NAG-1 expression was measured by ELISA. The data were analyzed for NAG-1 concentration by tumor type, sex, BMI, and age. NAG-1 concentration was lower in the plasma samples of patients with benign tumors, such as follicular adenoma and nodular hyperplasia than in those with malignant thyroid cancer, such as PTC, FVPTC, and FTC, but the difference was not statistically significant (Figure S1A). In addition, no difference was noted in NAG-1 concentrations according to sex and BMI (Figure S1B,C). Interestingly, the concentration of NAG-1 in the plasma increased with patient age [29] (Figure S1D). According to these data, the levels of mature serum NAG-1 change with age regardless of the patient's sex, BMI, or cancer type. Together, these results indicate that pro- 
and mature NAG-1 not only exhibit great potential as a biomarker for diagnosis but also as a therapeutic target for thyroid cancer.
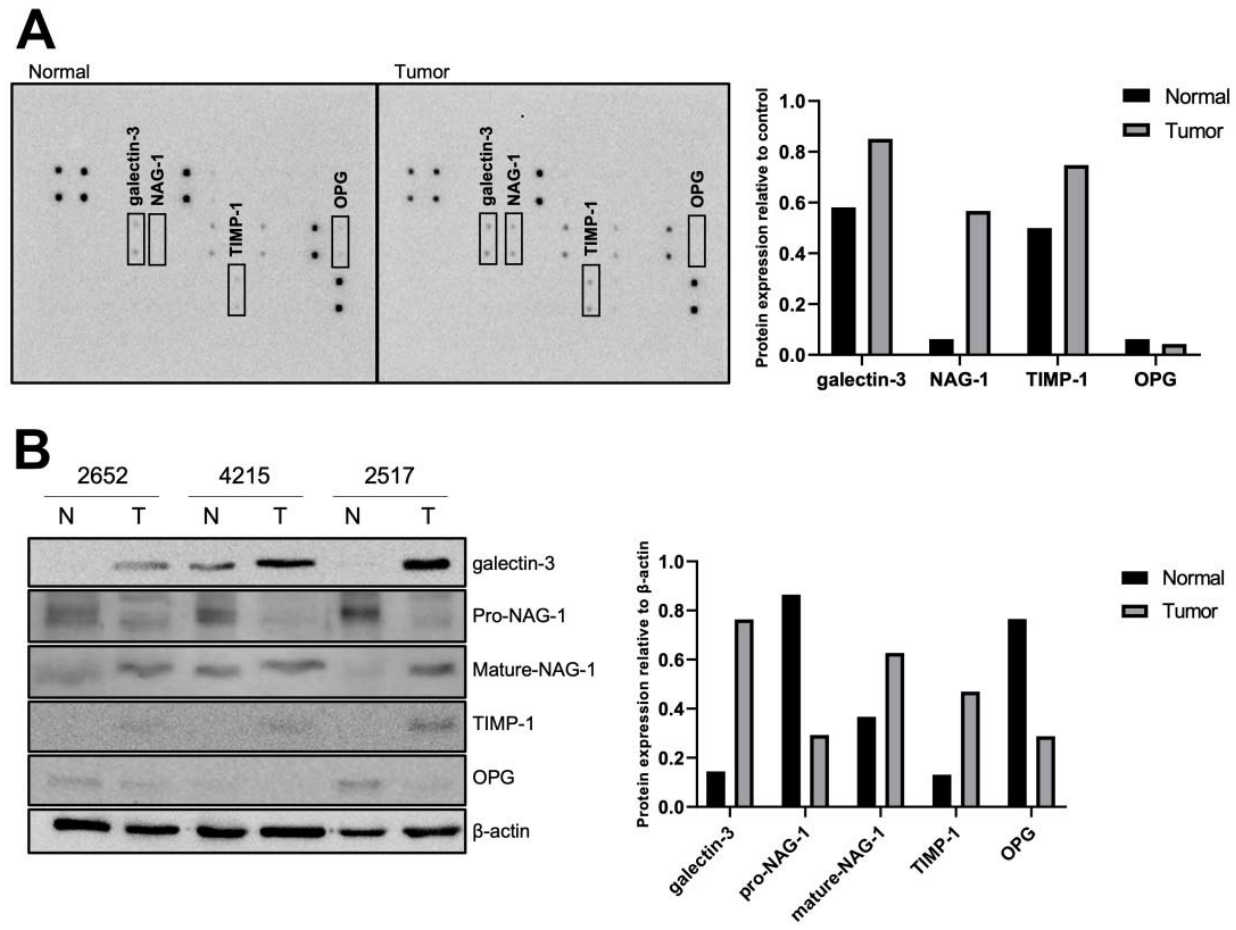

Figure 1. Antibody array using human thyroid tissues. (A) Antibody array (RayBio ${ }^{\circledR}$ C-Series Human Cancer Discovery Antibody Array 3, RayBiotech) showed that 30 cytokines related to cancer biology were differentially expressed between thyroid normal and tumor tissues. One pair of PTC samples was used to analyze the expression of these cytokines. Four different proteins (Galectin-3, NAG1/GDF15, TIMP-1, and osteoprotegerin) were selected as biomarker candidates for the diagnosis of thyroid cancer (rectangle). The right graph represents the intensity of each protein. (B) Western blot was performed using three pairs of PTC samples to confirm the data of antibody array. The protein expression of galectin-3, mature NAG-1, pro-NAG-1, TIMP-1, and OPG was examined using thyroid tissue samples. The right graph is from the average quantification of protein expression from three patients. N, thyroid normal tissue; $\mathrm{T}$, thyroid tumor tissue. The number of patients is indicated (see Table 1 for details). Uncropped versions of blots presented in Figures S2 and S3.

\subsection{Mature and Pro-NAG-1 Expression in Various Cancer Cells}

To identify whether various cancer cells express NAG-1 at the transcriptional level, we first measured the mRNA levels of NAG-1 in thyroid and other cancer cells. As shown in Figure 2A, BCPAP cells exhibited higher expression of NAG-1 mRNA among thyroid cancer cell lines, whereas U2OS osteosarcoma cells showed the highest NAG-1 mRNA expression. Since NAG-1 is synthesized as pro-NAG-1 and cleaved into mature NAG-1, western blot analysis was conducted to determine the mature and pro-NAG-1 expression in various cancer cell lines. Western blot analysis revealed that BCPAP cells showed higher NAG-1 expression in the cell lysates and conditioned medium among the thyroid cancer cells (Figure 2B), which was consistent with the RT-qPCR data. Among the non-thyroid cancer cells, BT-20 breast cancer cells and U2OS osteosarcoma cells expressed significant amounts of NAG-1 in cell lysates and conditioned media (Figure 2C).

\subsection{Quercetin Increases Pro-NAG-1 Levels but Not Mature NAG-1 Levels}

Since two forms of NAG-1 (mature and pro-) are differentially expressed in the cell lysates with opposing activities in cancer cells, we examined several compounds that increase pro-NAG-1 expression in thyroid cancer cells. BCPAP cells were treated with various 
anticancer compounds, such as phytochemicals and nonsteroidal anti-inflammatory drugs (NSAIDs). Among these, sulindac sulfide and quercetin dramatically increased pro-NAG-1 expression compared to DMSO treatment (Figure 3A). Treatment with sulindac sulfide (SS), trans-chalcone (TC), and quercetin (QUE) also increased pro-NAG-1 expression in a dosedependent manner (Figure 3B). Since quercetin treatment increased pro-NAG-1 expression among the tested compounds, cells were treated with different doses of quercetin, and proand mature NAG-1 expressions were measured. Interestingly, quercetin only increased pro-NAG-1 but did not alter the expression of mature NAG-1 in a dose-dependent manner (Figure 3C). This result indicates that pro-NAG-1 expression is preferentially increased by quercetin, and pro-NAG-1 is a chemotherapeutic target for thyroid cancer.

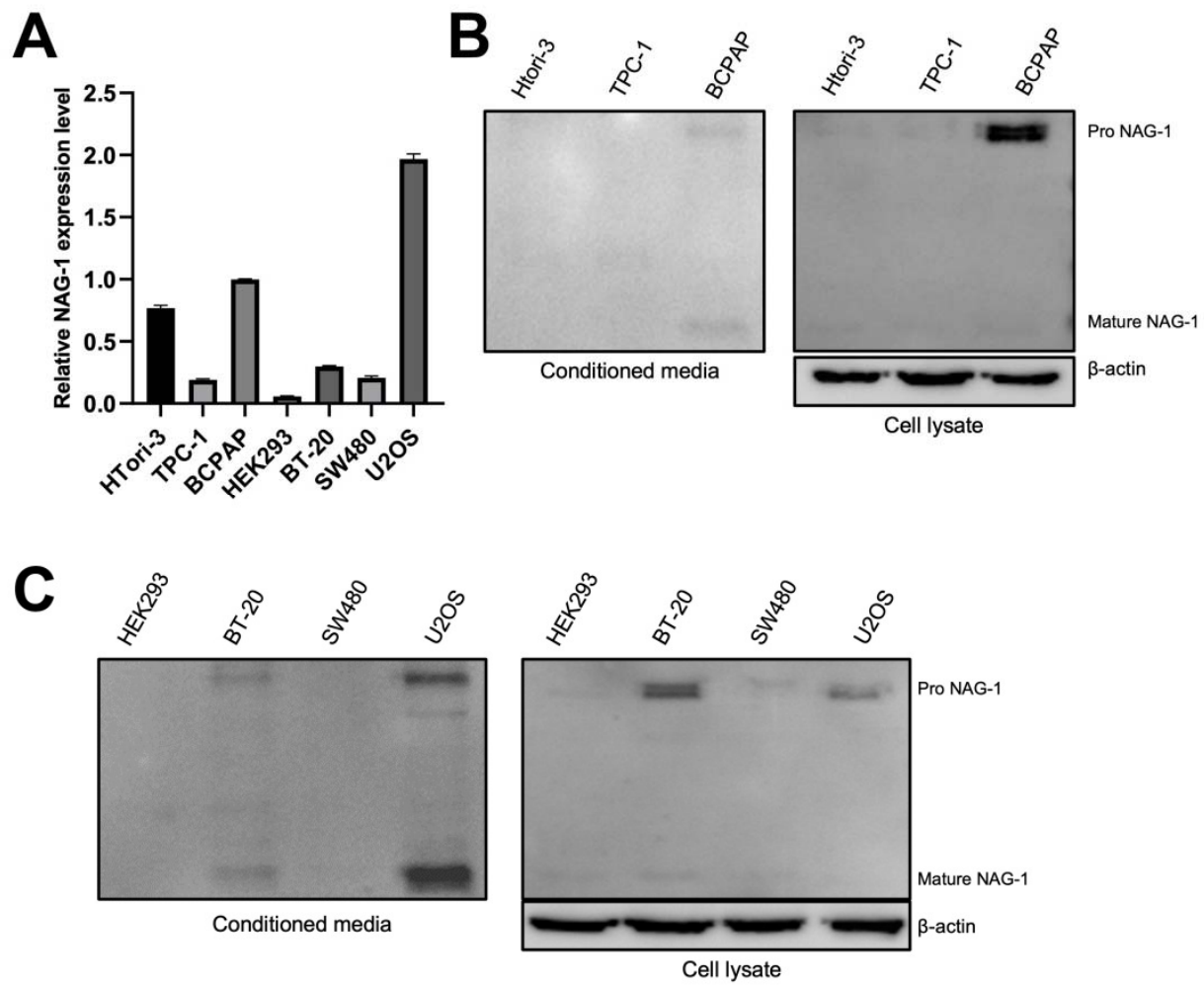

Figure 2. NAG-1 expression in various types of cancer cell lines. (A) Quantitative reverse transcriptase-polymerase chain reaction (RT-qPCR) was conducted using both thyroid (HTori-3, TPC-1, and BCPAP) and non-thyroid cell lines (HEK-293, BT-20, SW480, and U2OS). Analysis was performed in triplicate, and the graph shows the mRNA levels of NAG-1 expression compared with those of BCPAP cells. Western blot analysis using (B) thyroid and (C) non-thyroid cancer cells. Conditioned medium and total cell lysates were isolated as described in the Methods section, and NAG-1 antibodies against pro- and mature NAG-1 were hybridized into the membrane. Uncropped versions of blots presented in the Figures S4 and S5.

\subsection{Quercetin Induces Apoptosis and Cell Cycle Arrest}

To confirm the anticancer activity of quercetin, a high-throughput platform was used. Representative images showed reduced fluorescence intensity of SYTOX and MitoTracker in quercetin-treated cells (Figure 4A). Cell permeability was increased (Figure 4B), and mitochondrial membrane potential was decreased by quercetin treatment in a dose-dependent manner (Figure 4C), indicating apoptosis induction. Annexin V assay was performed to measure the percentage of apoptotic cells in quercetin-treated cells. The data showed that quercetin increased the percentage of apoptotic cells (Figure 4D). Additionally, PI staining data suggested that quercetin treatment affected cell cycle arrest at the $S$ phase (Figure 4E). Taken together, quercetin induced cell apoptosis and cell cycle arrest. 

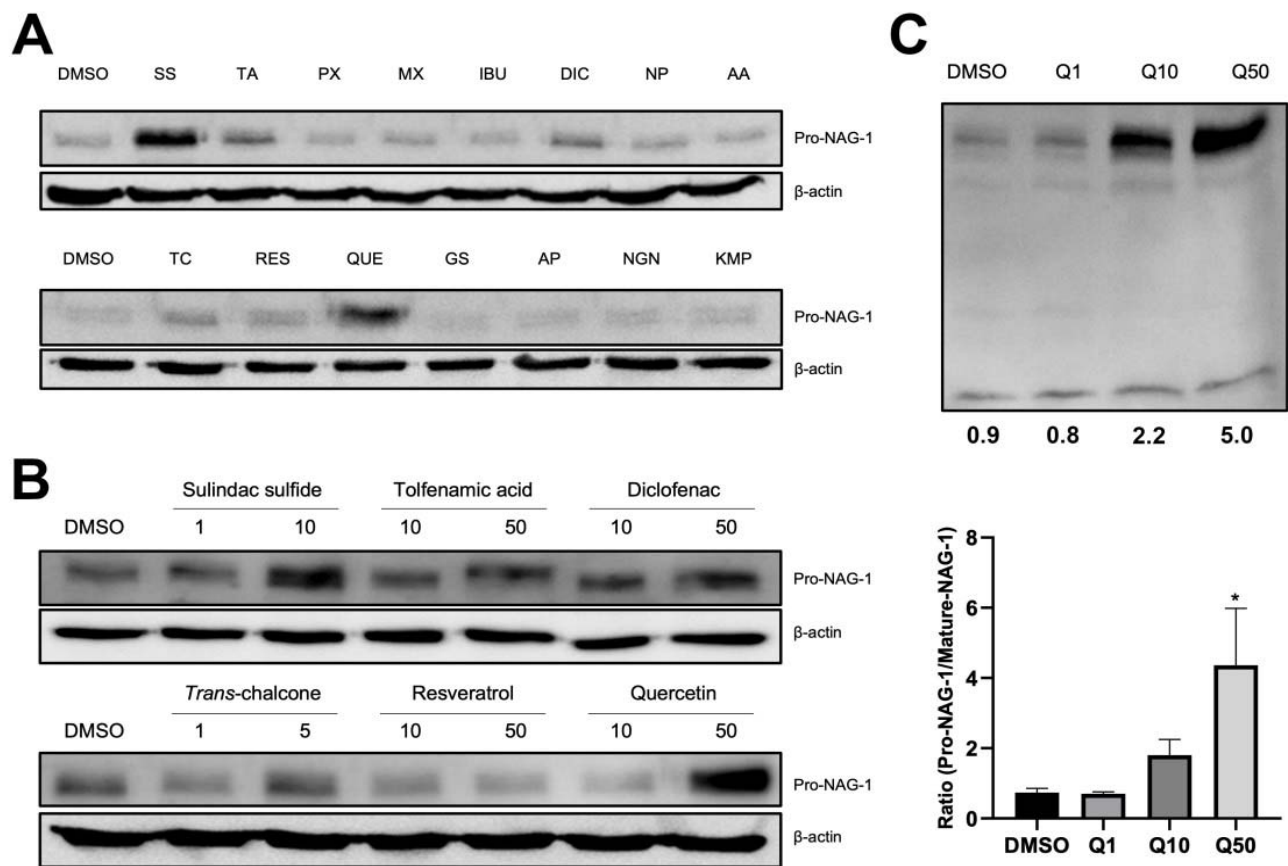

Figure 3. Pro-NAG-1/GDF15 expression in the presence of several anticancer compounds. (A) The human thyroid cancer cell line BCPAP was exposed to different nonsteroidal anti-inflammatory drugs (NSAIDs) and phytochemicals for $24 \mathrm{~h}$ with serum-free media (sulindac sulfide (SS): $10 \mu \mathrm{M}$, trans-chalcone (TC): $5 \mu \mathrm{M}$; tolfenamic acid (TA), piroxicam (PX), meloxicam (MX), ibuprofen (IBU), diclofenac (DIC), naproxen (NP), acetaminophen (AA), resveratrol (RES), quercetin (QUE), genistein $(\mathrm{GS})$, apigenin (AP), naringenin (NGN), and kaempferol (KMP): $50 \mu \mathrm{M})$. Cells were harvested, and the proteins were extracted with radioimmunoprecipitation assay (RIPA) buffer. Proteins were subjected to western blot to detect pro-NAG-1 and $\beta$-actin expression. (B) BCPAP cells were exposed to different doses (sulindac sulfide; $1,10 \mu \mathrm{M}$, trans-chalcone: $1,5 \mu \mathrm{M}$; others: $10,50 \mu \mathrm{M}$ ) of anticancer compounds for $24 \mathrm{~h}$ with serum-free media. Western blot analysis was conducted as described in the Methods section. (C) Quercetin at doses of 1,10, and $50 \mu \mathrm{M}$ were treated to BCPAP cells. Proand mature NAG-1 were detected by western blot. The bottom number represents the ratio of proand mature NAG-1 expression, three independent experiments and a statistical analysis were done. * $p<0.05$. Uncropped versions of blots presented in the Figures S6 and S7.

\subsection{Quercetin Increases NAG-1 Promoter Activity through $p 53, \mathrm{C} / E B P \alpha$, and $C / E B P \delta$}

To determine the mechanism by which quercetin affects NAG-1 expression at the transcriptional level, we examined NAG-1 promoter activity in the presence of quercetin. First, quercetin induced NAG-1 mRNA expression in a dose-dependent manner (Figure 5A). To elucidate the molecular mechanism, we conducted a dual-luciferase assay using several NAG-1 promoters linked to the luciferase gene. Several luciferase constructs, including pNAG-1-133/+70/LUC, pNAG-1-133/+41/LUC, pNAG-1-474/+41/LUC, pNAG-11086/+41/LUC, and pRL null construct, were co-transfected into BCPAP, and transfected cells were treated with DMSO or $50 \mu \mathrm{M}$ quercetin. After $24 \mathrm{~h}$ of incubation, luciferase activity was measured, and NAG-1 promoter activity was marginally increased by quercetin in all constructs (Figure 5B), indicating that the quercetin response element may be located within the -133 to +70 region. Furthermore, this promoter region was examined in the presence of quercetin, revealing that quercetin increased NAG-1 promoter activity in a dose-dependent manner (Figure 5C). Quercetin increases the level of p53 tumor suppressor protein in human colorectal cancer cells [30]. To investigate whether the increase in NAG-1 promoter activity depends on p53, we transfected an empty vector or p53 expression vector with pNAG-1-133/+70/LUC and pRL null and treated them with DMSO or quercetin. The luciferase activity was higher in the p53-transfected group (Figure 5D), indicating that quercetin increased NAG-1 promoter activity via p53 expression. However, since BCPAP 
is a p53 mutant cell line, we hypothesized that there would be another pathway. To identify additional factors that cause NAG-1 induction, we used the pNAG-1-133/+41/LUC construct to perform the dual-luciferase assay. ATF3, CREB, RAR, C/EBP $\alpha, \mathrm{C} / \mathrm{EBP} \delta$, or EGR-1 can bind to the NAG-1 promoter within the -133 bp region $[15,31,32]$. Thus, several expression vector plasmids were co-transfected with the NAG-1 promoter in BCPAP cells. As a result, $\mathrm{C} / \mathrm{EBP} \alpha$ and $\mathrm{C} / \mathrm{EBP} \delta$ levels were significantly increased compared to the empty vector (EV)-transfected group (Figure 5E), in a dose-dependent manner (Figure 5F). Taken together, quercetin may affect $\mathrm{C} / \mathrm{EBP} \alpha$ and $\mathrm{C} / \mathrm{EBP} \delta$ expression, followed by the induction of NAG-1 expression in BCPAP cells.
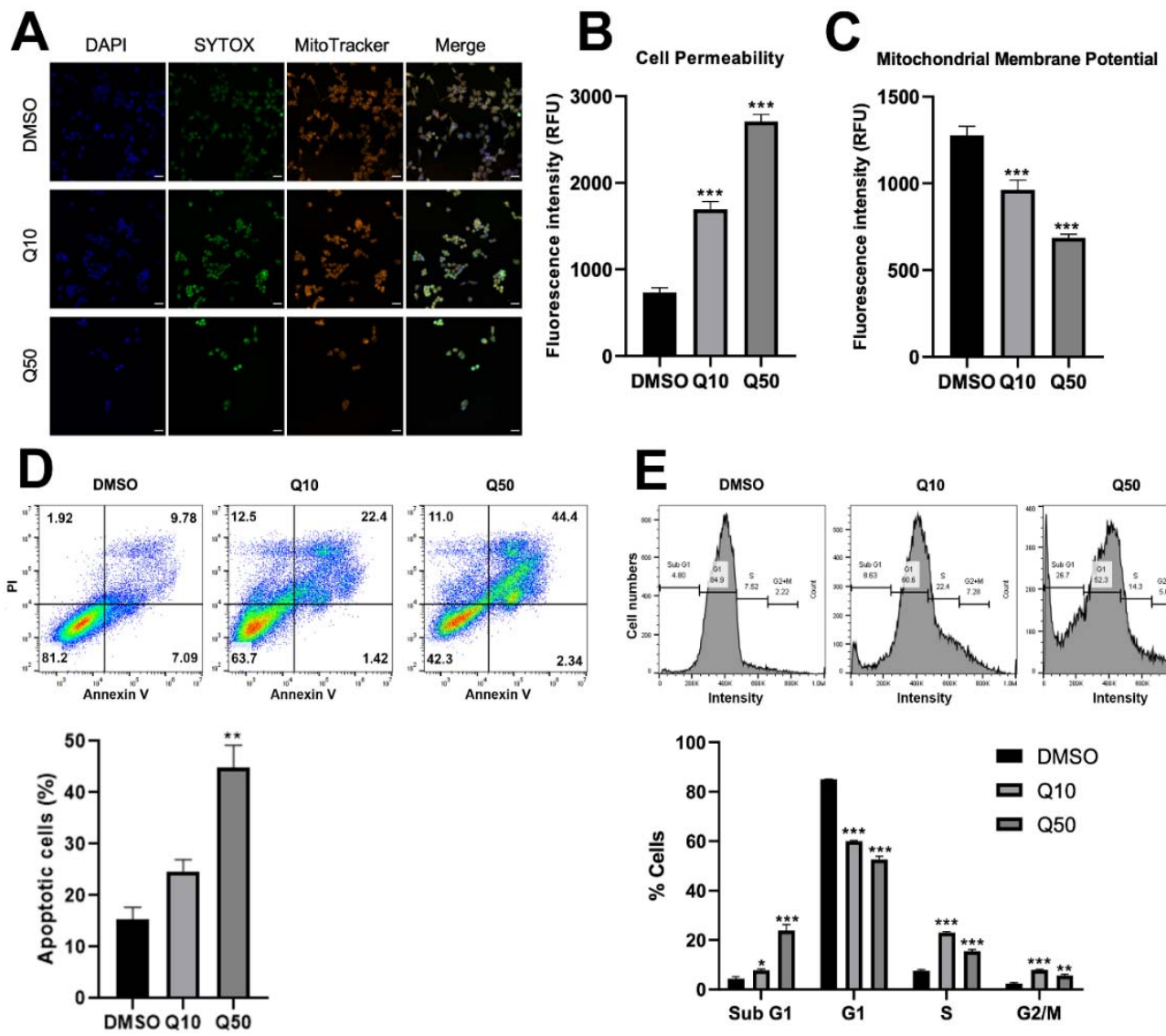

Figure 4. Quercetin induced apoptosis and cell cycle arrest in BCPAP cells. (A) BCPAP cells were subjected to high-content screening using the CellInsight CX7 LZR High-Content Screening (HCS) Platform (Thermo Fisher Scientific, Waltham, MA, USA), and representative images are shown. Cells were stained with $1 \mu \mathrm{g} / \mathrm{mL}$ Hoechst 33342, $100 \mathrm{nM}$ SYTOX ${ }^{\circledR}$ Green Nucleic Acid Stain (green), and 25 nM MitoTracker ${ }^{\circledR}$ Orange CMTMRos (orange) in Hanks' Balanced Salt Solution (HBSS) for 30 min. DMSO, vehicle; Q10, $10 \mu \mathrm{M}$ quercetin; Q50, $50 \mu \mathrm{M}$ quercetin. Magnification $=200 \times$, scale bar $=200 \mu \mathrm{m}$. CellInsight CX7 LZR High-Content Screening (HCS) Platform data were quantified and presented as changes in cell permeability (B) and mitochondrial membrane potential (C) as measured by the average intensities of SYTOX and MitoTracker. Values are expressed as the mean \pm the standard error of the mean (SEM). ${ }^{* * *} p<0.001$.(D) Apoptosis analysis using Annexin V/ propidium iodide (PI) staining. DMSO, vehicle; Q10, $10 \mu \mathrm{M}$ quercetin; $\mathrm{Q} 50,50 \mu \mathrm{M}$ quercetin. The bottom graph represents the percentage of cells in the early and late apoptotic populations. Results are representative of three independent experiments. ${ }^{* *} p<0.01$. (E) Cell cycle analysis using PI. The representative graph is shown at the top. The bottom graph indicates the different cell cycle populations in the presence of quercetin. Results are representative of three independent experiments. ${ }^{*} p<0.05,{ }^{* *} p<0.01$, and ${ }^{* * *} p<0.001$. 

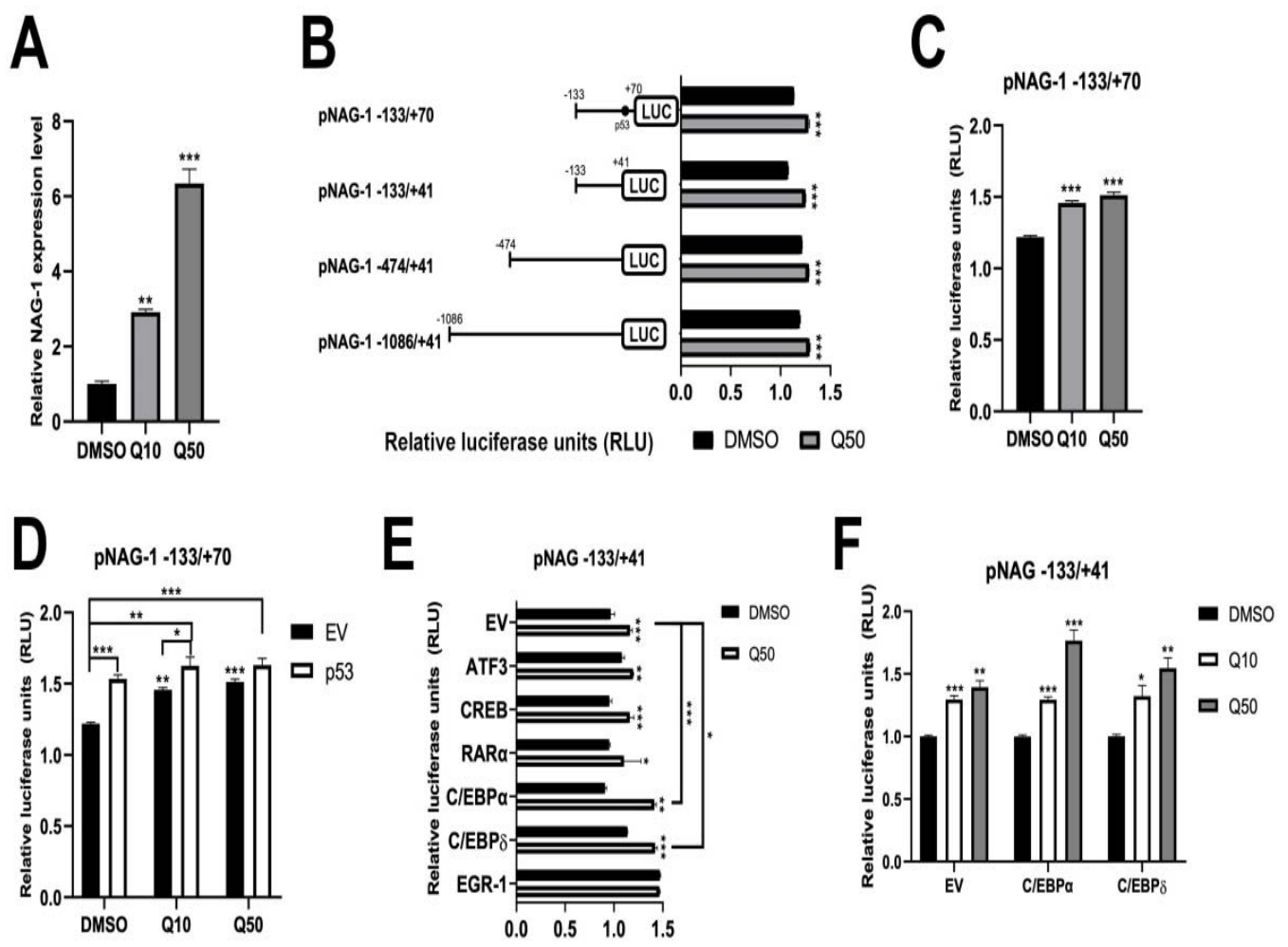

Figure 5. Quercetin increased NAG-1 promoter activity. (A) Quercetin increased NAG-1 expression at the transcriptional level. GAPDH was used as a control. DMSO, vehicle; Q10, $10 \mu \mathrm{M}$ quercetin; Q50, $50 \mu \mathrm{M}$ quercetin. Data are representative of three independent samples. ${ }^{* *} p<0.01$ and ${ }^{* * *} p<0.001$. (B) The pNAG-133/+70/LUC, pNAG-133/+41/LUC, pNAG474/+41/LUC, pNAG-1086/+41/LUC, and pRL null constructs were co-transfected into BCPAP cells, and cells were treated with dimethyl sulfoxide (DMSO) or Q50. Luciferase activity was measured using the Dual-Luciferase system. The X-axis represents relative luciferase units, and the schematic diagram of the NAG-1 promoter is indicated on the left of the figure. *** $p<0.001$. (C) DMSO or quercetin $(10$ and $50 \mu \mathrm{M})$ was treated in pNAG-1-133/+70/LUC containing the p53-binding site and pRL null-transfected BCPAP cells. ${ }^{* * *} p<0.001$. (D) BCPAP cells were co-transfected with pNAG-1-133/+70/LUC and pRL null constructs and then divided into two groups. One group was transfected with the empty vector (EV) and another group was transfected with the p53 expression vector. After $24 \mathrm{~h}$ of incubation, the transfected cells were treated with DMSO or quercetin for $24 \mathrm{~h} .{ }^{*} p<0.05,{ }^{* *} p<0.01$, and ${ }^{* * *} p<0.001$. (E) BCPAP cells were co-transfected with pNAG-1-133/+41/LUC and pRL null constructs and then divided into two groups. One group was transfected with the empty vector (EV) and another group was transfected with ATF3, CREB, RAR $\alpha, \mathrm{C} / \mathrm{EBP} \alpha, \mathrm{C} / \mathrm{EBP} \delta$, or EGR-1 expression vector. After $24 \mathrm{~h}$ of stabilization, the transfected cells were treated with DMSO or quercetin. Data are representative of three independent samples. ${ }^{*} p<0.05,{ }^{* *} p<0.01$, and ${ }^{* * *} p<0.001$. (F) pNAG-1 -133/+41/LUC- and pRL null-transfected BCPAP cells were treated with DMSO or quercetin $(10$ and $50 \mu \mathrm{M})$. Data are representative of three independent samples. All the luciferase experiments were conducted and represented as ${ }^{*} p<0.05,{ }^{* *} p<0.01$, and ${ }^{* *} p<0.001$.

\section{Discussion}

Although thyroid cancer is a common and relatively indolent cancer with a low mortality rate, some types of thyroid cancer show aggressive clinical features, such as rapid progression, lymph node, distant metastases, and even death from persistent and recurrent disease. Therefore, it is important to identify reliable and clinically applicable novel biomarkers for thyroid cancer diagnosis and prediction.

To elucidate this problem, we conducted an antibody array using papillary thyroid cancer and normal tissues. Four proteins were identified that showed increasing or decreasing expression in thyroid tumorigenesis (Figure 1A,B). Galectin-3 controls cellular proliferation and apoptosis in normal cells as well as malignant transformation and metastasis in cancer cells [33]. Galectin-3 is a notable protein marker for thyroid tumors, and we confirmed the induction of galectin-3 in an antibody array and western blot analysis (Figure 1A,B). The 
expression of TIMP-1 in the plasma and tissues of patients with cancer is highly increased, with more significant levels related to worse clinical results in various cancers, including prostate and colon cancers [34]. However, it is not clear whether TIMP-1 serves only as a biomarker of cancer progression or functions to promote cancer progression; thus, it could serve as an important cancer therapeutic target in thyroid cancer. Osteoprotegerin, which is engaged in many biological systems, plays a key role in the regulation of bone resorption [35]. The use of serum OPG as a prognostic marker has also been investigated in breast cancer and was found to be a potential diagnostic marker [36]. However, OPG was increased in normal thyroid tissues according to antibody array and western blot data, highlighting the differences between tissue and serum OPG levels. The exact biological activity of OPG in thyroid cancer remains to be elucidated.

NAG-1/GDF15 has been identified as an NSAID-induced gene [8]. It is by several anti-cancer agents, including phytochemicals [37], NSAIDs [27], and PPAR $\gamma$ ligands [38]. Although the biological activity of NAG-1 in obesity has been well established [39], the role of NAG-1 in tumorigenesis is contradictory in several cancers [7]. In general, an antitumorigenic effect during tumor development was observed in transgenic mice expressing NAG-1 [40,41]. In contrast, most results showing the pro-cancer activity of NAG-1 were obtained from in vitro experiments using cultured cells [42]. Recently, Kang et al. reported that NAG-1/GDF15 is a mitokine that increases the invasiveness of thyroid cancer [43]. This discrepancy may result from the different activities of pro-NAG-1 and mature NAG-1, the different expression of mature and pro-NAG-1, or multiple activities of NAG-1 depending on the cell context. In this study, antibody array data indicated that NAG-1 expression was increased in tumor tissues due to the abundant expression of mature NAG-1. However, size differentiation by western blot analysis clearly indicated that pro-NAG-1 was more highly expressed in normal tissues, whereas mature NAG-1 was more highly expressed in tumor tissues. This is consistent with our previous report that NAG-1 may function as a moonlighting protein in tumorigenesis [12,14].

Many pharmacological approaches have been proposed for conventional drug therapies. In the present study, we screened dietary compounds, phytochemicals, and NSAIDs to examine their effects on pro-NAG-1 induction in thyroid cancer cells. The levels of pro-NAG-1 were increased by sulindac sulfide or quercetin, a conventional NSAID and a phytochemical, respectively; these have been reported to increase pro-NAG-1 levels and exert anticancer activity in several cancers [44,45]. Interestingly, in the presence of quercetin, only pro-NAG-1 expression was increased in BCPAP cells (Figure 3C). This result supports the fact that many phytochemicals induce anticancer activities via NAG-1 expression, even though mature NAG-1 is linked to pro-tumorigenic activity. Although detailed mechanisms need to be elucidated, this is the first report to suggest that a phytochemical preferentially increases the expression of pro-NAG-1 but not that of mature NAG-1 in BCPAP cells.

Several transcriptional factors have been shown to increase NAG-1 expression at the transcriptional level. Among these, $\mathrm{C} / \mathrm{EBP} \alpha$ and $\mathrm{C} / \mathrm{EBP} \delta$ were identified as NAG-1 inducers at the transcriptional level. The overexpression of CCAAT/enhancer-binding protein $(\mathrm{C} / \mathrm{EBP}) \alpha, \beta$, and $\delta$ caused a significant increase in basal and capsaicin-induced NAG-1 promoter activity [46], and quercetin increased C/EBP $\beta$ mRNA and protein expression [47]. Thus, it is likely that quercetin increases the expression of C/EBP isotypes, followed by increased NAG-1 expression. However, the detailed molecular mechanism by which quercetin affects NAG-1 expression at the transcriptional level remains to be elucidated.

Taken together, this study highlights a potential biomarker for the diagnosis of thyroid cancer, especially in differentiating between pro- and mature NAG-1. Further investigation may be required to elucidate the molecular mechanism of quercetin-induced NAG-1 expression; however, our data indicate that $\mathrm{C} / \mathrm{EBP}$ proteins contribute at least, in part, to the quercetin-induced NAG-1 expression (Figure 6). 


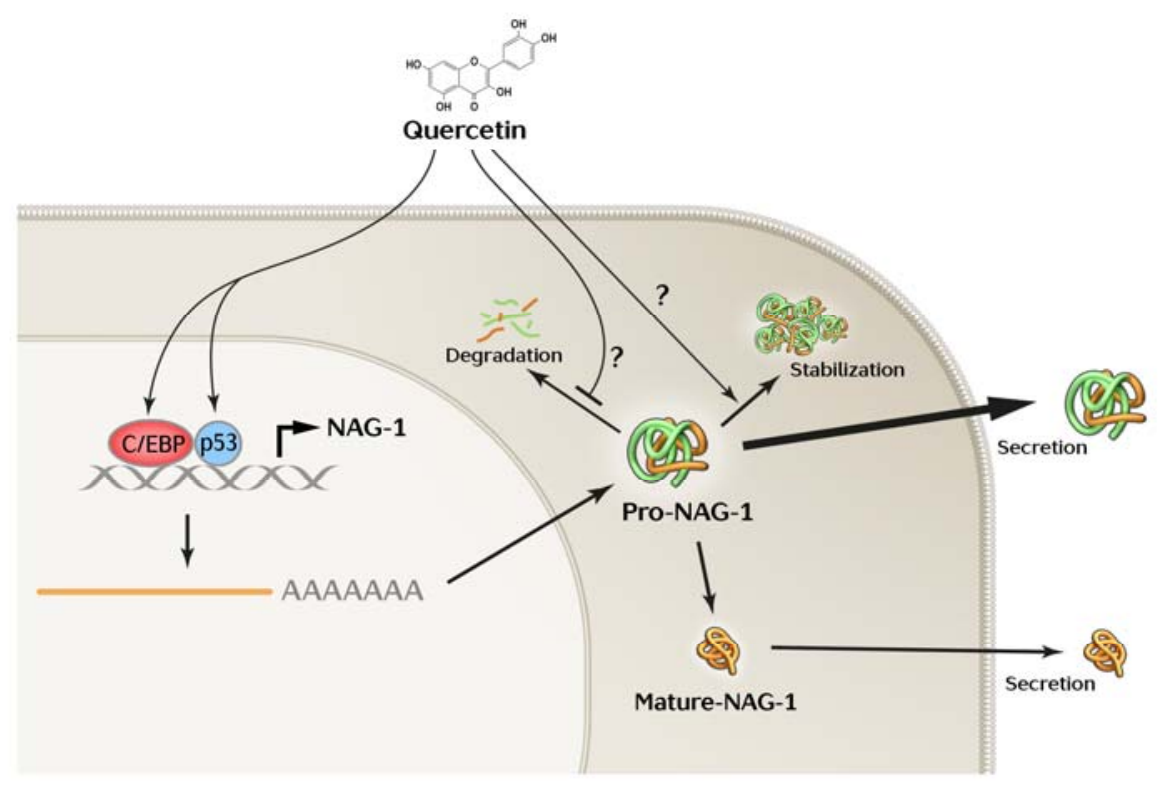

Figure 6. Proposed mechanism by which pro-NAG-1 plays an anti-tumorigenic role in thyroid cancer. Pro-NAG-1 and mature NAG-1 are produced in thyroid tissues and cancer cells. Quercetin Table S1 in human thyroid cancer, leading to an increase in pro-NAG-1 only, and not mature NAG-1.

\section{Conclusions}

The expression of mature NAG-1 in BCPAP cells was not significantly altered in the presence of quercetin, but pro-NAG-1 expression was significantly higher. This report suggests that pro-NAG-1 may be used as a therapeutic target in thyroid cancer.

Supplementary Materials: The following are available online at https://www.mdpi.com/article/10 .3390 / cancers13123022/s1, Figure S1. NAG-1/GDF-15 concentration was increased by age. Figure S2. Uncropped Figure 1A. Figure S3. Uncropped Figure 1B. Figure S4. Uncropped Figure 2B. Figure S5. Uncropped Figure 2C. Figure S6. Uncropped Figure 3A, 3B. Figure S7. Uncropped Figure 3C. Table S1: NAG-1 RT-qPCR.

Author Contributions: Y.H., J.R., and S.J.B. conceived the study and designed the experiments. Y.H., J.L., and H.M. performed the experiments and collected the results. C.H.R., J.S., Y.-S.J., J.R., and S.J.B. interpreted the results. Y.H., J.R., and S.J.B. wrote and revised the manuscript. All authors have read and agreed to the published version of the manuscript.

Funding: This work was supported by the Research Institute for Veterinary Science and BK21 PLUS Program for Creative Veterinary Science Research Center, Seoul National University, and by a National Research Foundation of Korea (NRF) grant funded by the Korean government (2018R1A2B2002923) to S.J.B. This work was also supported by a clinical research grant (NCC1810150) provided by the National Cancer Center to J.R., C.H.R., and S.J.B.

Institutional Review Board Statement: The study was approved by the Institutional Review Board of the National Cancer Center (NCC-1810150), and all the experiments were conducted in accordance with the relevant guidelines and regulations.

Informed Consent Statement: Informed consent was obtained from all subjects involved in the study.

Data Availability Statement: Not applicable.

Acknowledgments: We thank Dahyeon Yoon from the Department of Veterinary Medicine, College of Veterinary Medicine, Seoul National University, for her technical support.

Conflicts of Interest: The authors declare no conflict of interest. 


\section{References}

1. Siegel, R.L.; Miller, K.D.; Jemal, A. Cancer statistics, 2019. CA Cancer J. Clin. 2019, 69, 7-34. [CrossRef]

2. Hong, S.; Won, Y.-J.; Lee, J.J.; Jung, K.-W.; Kong, H.-J.; Im, J.-S.; Seo, H.G. The Community of Population-Based Regional Cancer Registries Cancer Statistics in Korea: Incidence, Mortality, Survival, and Prevalence in 2018. Cancer Res. Treat. 2021, 53, 301-315. [CrossRef]

3. Fusco, A.; Grieco, M.; Santoro, M.; Berlingieri, M.T.; Pilotti, S.; Pierotti, M.A.; Della Porta, G.; Vecchio, G. A new oncogene in human thyroid papillary carcinomas and their lymph-nodal metastases. Nat. Cell Biol. 1987, 328, 170-172. [CrossRef] [PubMed]

4. Giordano, T.J.; Kuick, R.; Thomas, D.G.; Misek, D.E.; Vinco, M.; Sanders, D.; Zhu, Z.; Ciampi, R.; Roh, M.; Shedden, K.; et al. Molecular classification of papillary thyroid carcinoma: Distinct BRAF, RAS, and RET/PTC mutation-specific gene expression profiles discovered by DNA microarray analysis. Oncogene 2005, 24, 6646-6656. [CrossRef]

5. Raman, P.; Koenig, R.J. Pax-8-PPAR- $\gamma$ fusion protein in thyroid carcinoma. Nat. Rev. Endocrinol. 2014, 10, 616-623. [CrossRef] [PubMed]

6. Herrmann, M.A.; Hay, I.D.; Bartelt, D.H.; Ritland, S.R.; Dahl, R.J.; Grant, C.S.; Jenkins, R.B. Cytogenetic and molecular genetic studies of follicular and papillary thyroid cancers. J. Clin. Investig. 1991, 88, 1596-1604. [CrossRef] [PubMed]

7. Baek, S.J.; Eling, T. Growth differentiation factor 15 (GDF15): A survival protein with therapeutic potential in metabolic diseases. Pharmacol. Ther. 2019, 198, 46-58. [CrossRef]

8. Baek, S.J.; Kim, K.S.; Nixon, J.B.; Wilson, L.C.; Eling, T.E. Cyclooxygenase inhibitors regulate the expression of a TGF-beta superfamily member that has proapoptotic and antitumorigenic activities. Mol. Pharmacol. 2001, 59, 901-908. [CrossRef] [PubMed]

9. Mullican, S.E.; Lin-Schmidt, X.; Chin, C.-N.; Chavez, J.A.; Furman, J.L.; Armstrong, A.A.; Beck, S.C.; South, V.J.; Dinh, T.Q.; Cash-Mason, T.D.; et al. GFRAL is the receptor for GDF15 and the ligand promotes weight loss in mice and nonhuman primates. Nat. Med. 2017, 23, 1150-1157. [CrossRef]

10. Mehta, R.S.; Song, M.; Bezawada, N.; Wu, K.; Garcia-Albeniz, X.; Morikawa, T.; Fuchs, C.S.; Ogino, S.; Giovannucci, E.L.; Chan, A.T. A Prospective Study of Macrophage Inhibitory Cytokine-1 (MIC-1/GDF15) and Risk of Colorectal Cancer. J. Natl. Cancer Inst. 2014, 106, dju016. [CrossRef]

11. Breit, S.N.; Johnen, H.; Cook, A.; Tsai, V.W.W.; Mohammad, M.G.; Kuffner, T.; Zhang, H.P.; Marquis, C.; Jiang, L.; Lockwood, G.; et al. The TGF- $\beta$ superfamily cytokine, MIC-1/GDF15: A pleotrophic cytokine with roles in inflammation, cancer and metabolism. Growth Factors 2011, 29, 187-195. [CrossRef]

12. Min, K.-W.; Liggett, J.L.; Silva, G.; Wu, W.W.; Wang, R.; Shen, R.-F.; Eling, T.; Baek, S.J. NAG-1/GDF15 accumulates in the nucleus and modulates transcriptional regulation of the Smad pathway. Oncogene 2016, 35, 377-388. [CrossRef]

13. Lee, J.; Kim, I.; Yoo, E.; Baek, S.J. Competitive inhibition by NAG-1/GDF-15 NLS peptide enhances its anti-cancer activity. Biochem. Biophys. Res. Commun. 2019, 519, 29-34. [CrossRef]

14. Min, K.-W.; Lee, S.-H.; Baek, S.J. Moonlighting proteins in cancer. Cancer Lett. 2016, 370, 108-116. [CrossRef] [PubMed]

15. Lee, S.-H.; Cekanova, M.; Baek, S.J. Multiple mechanisms are involved in 6-gingerol-induced cell growth arrest and apoptosis in human colorectal cancer cells. Mol. Carcinog. 2008, 47, 197-208. [CrossRef] [PubMed]

16. Lee, S.-H.; Kim, J.-S.; Yamaguchi, K.; Eling, T.E.; Baek, S.J. Indole-3-carbinol and 3,3'-diindolylmethane induce expression of NAG-1 in a p53-independent manner. Biochem. Biophys. Res. Commun. 2005, 328, 63-69. [CrossRef]

17. Lee, S.-H.; Min, K.-W.; Zhang, X.; Baek, S.J. 3,3'-Diindolylmethane induces activating transcription factor 3 (ATF3) via ATF4 in human colorectal cancer cells. J. Nutr. Biochem. 2013, 24, 664-671. [CrossRef] [PubMed]

18. Lee, S.-H.; Richardson, R.L.; Dashwood, R.H.; Baek, S.J. Capsaicin represses transcriptional activity of $\beta$-catenin in human colorectal cancer cells. J. Nutr. Biochem. 2012, 23, 646-655. [CrossRef]

19. Yoo, E.; Lee, J.; Lertpatipanpong, P.; Ryu, J.; Kim, C.-T.; Park, E.-Y.; Baek, S.J. Anti-proliferative activity of A. Oxyphylla and its bioactive constituent nootkatone in colorectal cancer cells. BMC Cancer 2020, 20, 1-12. [CrossRef]

20. Hashemzaei, M.; Far, A.D.; Yari, A.; Heravi, R.E.; Tabrizian, K.; Taghdisi, S.M.; Sadegh, S.E.; Tsarouhas, K.; Kouretas, D.; Tzanakakis, G.; et al. Anticancer and apoptosis-inducing effects of quercetin in vitro and in vivo. Oncol. Rep. 2017, 38, 819-828. [CrossRef]

21. Gol, R.M.; Kheirouri, S. The Effects of Quercetin on the Apoptosis of Human Breast Cancer Cell Lines MCF-7 and MDA-MB-231: A Systematic Review. Nutr. Cancer 2021, 1-18. [CrossRef]

22. Lan, C.-Y.; Chen, S.-Y.; Kuo, C.-W.; Lu, C.-C.; Yen, G.-C. Quercetin facilitates cell death and chemosensitivity through RAGE/PI3K/AKT/mTOR axis in human pancreatic cancer cells. J. Food Drug Anal. 2019, 27, 887-896. [CrossRef] [PubMed]

23. Ward, A.B.; Mir, H.; Kapur, N.; Gales, D.N.; Carriere, P.P.; Singh, S. Quercetin inhibits prostate cancer by attenuating cell survival and inhibiting anti-apoptotic pathways. World J. Surg. Oncol. 2018, 16, 1-12. [CrossRef] [PubMed]

24. Hisaka, T.; Sakai, H.; Sato, T.; Goto, Y.; Nomura, Y.; Fukutomi, S.; Fujita, F.; Mizobe, T.; Nakashima, O.; Tanigawa, M.; et al. Quercetin Suppresses Proliferation of Liver Cancer Cell Lines In Vitro. Anticancer. Res. 2020, 40, 4695-4700. [CrossRef]

25. Altundag, E.M.; Kasacı, T.; Yılmaz, A.M.; Karademir, B.; Koçtürk, S.; Taga, Y.; Yalçın, A.S. Quercetin-Induced Cell Death in Human Papillary Thyroid Cancer (B-CPAP) Cells. J. Thyroid. Res. 2016, 2016, 1-10. [CrossRef]

26. Celano, M.; Maggisano, V.; Bulotta, S.; Allegri, L.; Pecce, V.; Abballe, L.; Damante, G.; Russo, D. Quercetin improves the effects of sorafenib on growth and migration of thyroid cancer cells. Endocr. 2019, 67, 496-498. [CrossRef] 
27. Baek, S.J.; Horowitz, J.M.; Eling, T.E. Molecular Cloning and Characterization of Human Nonsteroidal Anti-inflammatory Drug-activated Gene Promoter. J. Biol. Chem. 2001, 276, 33384-33392. [CrossRef]

28. Zhang, H.; Zhang, W.; Tu, X.; Niu, Y.; Li, X.; Qin, L.; Yang, Z.; Su, Q. Elevated serum growth differentiation factor 15 levels are associated with thyroid nodules in type 2 diabetes aged over 60 years. Oncotarget 2017, 8, 41379-41386. [CrossRef] [PubMed]

29. Tanaka, T.; Biancotto, A.; Moaddel, R.; Moore, A.Z.; Gonzalez-Freire, M.; Aon, M.A.; Candia, J.; Zhang, P.; Cheung, F.; Fantoni, G.; et al. Plasma proteomic signature of age in healthy humans. Aging Cell 2018, 17, e12799. [CrossRef]

30. Lim, J.H.; Park, J.-W.; Min, D.S.; Chang, J.-S.; Lee, Y.H.; Park, Y.B.; Choi, K.S.; Kwon, T.K.; Lim, J.H.; Park, J.-W.; et al. NAG-1 up-regulation mediated by EGR-1 and p53 is critical for quercetin-induced apoptosis in HCT116 colon carcinoma cells. Apoptosis 2006, 12, 411-421. [CrossRef]

31. Lee, S.-H.; Bahn, J.H.; Whitlock, N.C.; Baek, S.J. Activating transcription factor 2 (ATF2) controls tolfenamic acid-induced ATF3 expression via MAP kinase pathways. Oncogene 2010, 29, 5182-5192. [CrossRef] [PubMed]

32. Nualsanit, T.; Rojanapanthu, P.; Gritsanapan, W.; Lee, S.-H.; Lawson, D.; Baek, S.J. Damnacanthal, a noni component, exhibits antitumorigenic activity in human colorectal cancer cells. J. Nutr. Biochem. 2012, 23, 915-923. [CrossRef]

33. Sumana, B.S.; Shashidhar, S.; Shivarudrappa, A.S. Galectin-3 Immunohistochemical Expression in Thyroid Neoplasms. J. Clin. Diagn. Res. 2015, 9, EC07-EC11. [CrossRef] [PubMed]

34. Hawthorn, L.; Stein, L.; Varma, R.; Wiseman, S.; Loree, T.; Tan, D. TIMP1 and SERPIN-A overexpression and TFF3 and CRABP1 underexpression as biomarkers for papillary thyroid carcinoma. Head Neck 2004, 26, 1069-1083. [CrossRef]

35. Infante, M.; Fabi, A.; Cognetti, F.; Gorini, S.; Caprio, M.; Fabbri, A. RANKL/RANK/OPG system beyond bone remodeling: Involvement in breast cancer and clinical perspectives. J. Exp. Clin. Cancer Res. 2019, 38, 1-18. [CrossRef] [PubMed]

36. Rachner, T.D.; Kasimir-Bauer, S.; Göbel, A.; Erdmann, K.; Hoffmann, O.; Browne, A.J.; Wimberger, P.; Rauner, M.; Hofbauer, L.C.; Kimmig, R.; et al. Prognostic Value of RANKL/OPG Serum Levels and Disseminated Tumor Cells in Nonmetastatic Breast Cancer. Clin. Cancer Res. 2019, 25, 1369-1378. [CrossRef]

37. Yoon, J.-H.; Baek, S.J. Molecular Targets of Dietary Polyphenols with Anti-inflammatory Properties. Yonsei Med. J. 2005, 46, 585-596. [CrossRef]

38. Baek, S.J.; Wilson, L.C.; Hsi, L.C.; Eling, T.E. Troglitazone, a Peroxisome Proliferator-activated Receptor $\gamma($ PPAR $\gamma$ ) Ligand, Selectively Induces the Early Growth Response-1 Gene Independently of PPAR $\gamma$. J. Biol. Chem. 2003, 278, 5845-5853. [CrossRef]

39. Tsai, V.W.; Husaini, Y.; Sainsbury, A.; Brown, D.A.; Breit, S.N. The MIC-1/GDF15-GFRAL Pathway in Energy Homeostasis: Implications for Obesity, Cachexia, and Other Associated Diseases. Cell Metab. 2018, 28, 353-368. [CrossRef]

40. Baek, S.J.; Okazaki, R.; Lee, S.-H.; Martinez, J.; Kim, J.-S.; Yamaguchi, K.; Mishina, Y.; Martin, D.W.; Shoieb, A.; Mcentee, M.F.; et al. Nonsteroidal Anti-Inflammatory Drug-Activated Gene-1 Over Expression in Transgenic Mice Suppresses Intestinal Neoplasia. Gastroenterol. 2006, 131, 1553-1560. [CrossRef]

41. Cekanova, M.; Lee, S.-H.; Donnell, R.L.; Sukhthankar, M.; Eling, T.E.; Fischer, S.M.; Baek, S.J. Nonsteroidal Anti-inflammatory Drug-Activated Gene-1 Expression Inhibits Urethane-Induced Pulmonary Tumorigenesis in Transgenic Mice. Cancer Prev. Res. 2009, 2, 450-458. [CrossRef]

42. Li, C.; Wang, J.; Kong, J.; Tang, J.; Wu, Y.; Xu, E.; Zhang, H.; Lai, M. GDF15 promotes EMT and metastasis in colorectal cancer. Oncotarget 2015, 7, 860-872. [CrossRef]

43. Kang, Y.E.; Kim, J.M.; Lim, M.A.; Lee, S.E.; Yi, S.; Kim, J.T.; Oh, C.; Liu, M.L.; Jin, Y.; Jung, S.-N.; et al. Growth Differentiation Factor 15 is a Cancer Cell-Induced Mitokine That Primes Thyroid Cancer Cells for Invasiveness. Thyroid. 2021, 31, 772-786. [CrossRef]

44. Baek, S.J.; Wilson, L.C.; Lee, C.-H.; Eling, T.E. Dual Function of Nonsteroidal Anti-Inflammatory Drugs (NSAIDs): Inhibition of Cyclooxygenase and Induction of NSAID-Activated Gene. J. Pharmacol. Exp. Ther. 2002, 301, 1126-1131. [CrossRef]

45. Yang, M.H.; Kim, J.; Khan, I.A.; Walker, L.A.; Khan, S.I. Nonsteroidal anti-inflammatory drug activated gene-1 (NAG-1) modulators from natural products as anti-cancer agents. Life Sci. 2014, 100, 75-84. [CrossRef] [PubMed]

46. Lee, S.-H.; Krisanapun, C.; Baek, S.J. NSAID-activated gene-1 as a molecular target for capsaicin-induced apoptosis through a novel molecular mechanism involving GSK3 C/EBP and ATF3. Carcinog. 2010, 31, 719-728. [CrossRef] [PubMed]

47. Galleggiante, V.; De Santis, S.; Liso, M.; Verna, G.; Sommella, E.; Mastronardi, M.; Campiglia, P.; Chieppa, M.; Serino, G. Quercetin-Induced miR-369-3p Suppresses Chronic Inflammatory Response Targeting C/EBP- $\beta$. Mol. Nutr. Food Res. 2019, 63, e1801390. [CrossRef] [PubMed] 